\title{
Bilingual Education vs English-only Approach at Australia's Northern Territory Schools
}

\author{
Fadhlur Rahman \\ Monash University, Clayton, Australia \\ frah0002@student.monash.edu
}

\begin{abstract}
ARTICLE HISTORY
Received : 2020-03-27

Revised : 2020-04-03

Accepted : 2020-04-26

\section{KEYWORDS}

English-Only Approach

Bilingual Education

Northern Territory (NT)

Australia
\end{abstract}

\begin{abstract}
The present library research highlights the "English-only" approach used in the Aboriginal classrooms in Northern Territory (NT) schools, Australia. This library study collects its data from five decades (1968-2018) of research and theorisation on the implementation of English instruction at Indigenous classrooms in Australia by referring to the changes of approaches from bilingual instruction policy to the current "English-only" approach. The writer then reports the problems occurred in the implementation of this approach in the specific classroom interaction. Factors like socio-cultural gap and dysfunctional discourse were found to be influencing the ineffective English-only classroom in the NT schools. What alternatives may have been tried in the Northern territory schools and to what degree of success?
\end{abstract}

\section{Introduction}

In a global multilingual context, Australia has been identified as one of the hotspots for language endangerment (Anderson and Harisson, 2007). According to the National Indigenous Languages survey in 2005, from 250 Indigenous languages about 110 are critically endangered. 145 of Aboriginal languages are currently acknowledged, and Northern Territory (NT) is exceptionally known as one of the most linguistically diverse areas in Australia (Mufwene and Vigouroux 2012; Meakins 2014; Devlin et al., 2017). There are at least fourteen languages are considered strong and still spoken by the Aboriginal inhabitants, where twelve are in the Northern Territory (Marmion et al., 2014; Biddle, 2014). In this sense, children of the Aboriginal inhabitants in NT may face linguistic challenges in the form of "English-only" approach created in school's setting, including the apparent 'invisibility' of their linguistic repertoire (Moses \& Wigglesworth, 2008). The implementation of this approach means that the vast majority of Indigenous children are being forced to submerge into the target language, which is standard Australian English (Wigglesworth et al., 2018). As a result, Indigenous students have insufficient participation in the classroom as they scarcely display their linguistic skill and knowledge (Moses \& Wigglesworth, 2008).

Therefore, this library research aims to critically evaluate and discuss the effectiveness of "Englishonly" approach in NT school's system. In this research, the writer argues that the "English-only" approach precludes the active participation of indigenous students in the classroom. Hence, alternatives approach that leads to the successful output of effective communication in NT schools setting is required.

\subsection{Historical Overview: Bilingual to English-Only}

Prior to the existence of English-only approach in NT Aboriginal classrooms, Robert Menzies (The Australian Prime Minister) in 1950 came up with the idea of instigating a "bilingual education" for remote students in NT schools (Devlin et al., 2017). Since then, the notion of bilingual education was viewed as the most desirable approach, however, only after twenty-two years later the program was finally launched by The Australian Government (Wigglesworth et al., 2018). Principally, the rationale of bilingual instruction is that children should first fully develop their native tongue before they can accomplish educational knowledge in a second language (Manning \& Baruth, 2004). In practical terms, this means that Indigenous children must be instructed and educated to read and write in their mother tongue before they are taught those skills in English (Chavez \& Amselle, 1997). Nonetheless, several models of bilingual education have been executed in NT schools, but the practical implementation of such programs is often far from ideal.

According to Lowell \& Devlin (1998), there was an attempt to discontinue NT bilingual education program in 1998. Although some brave schools have been struggled to maintain the policy, bilingual education was practically gone. With the loss of this program, the bilingual team teaching in most schools 
has gone as well. In this sense, non-Aboriginal teacher (who speak only English) employed the English-only approach as the teaching and learning instruction.

Therefore, the miscommunication between nonAboriginal teachers and Indigenous students seems commonly taking place. Further, in many cases, the effectiveness of classroom instruction and guideline might be seriously lessened due to the socio-cultural and linguistics contrast between the Aboriginal students and the non-Indigenous instructor. As a consequence, Indigenous children could not comprehend the teaching-learning instruction; hence, many students are becoming less and less motivated to attend school regularly.

Later in 2008, the Government initiated the school policy that state "the first four hours of every school day should be taught in English", this arrangement is, thus, undermining the already beleaguered bilingual program (Simpson et al., 2009). A change in this policy was promptly proclaimed, without any systematic consultation and research (Wilkins, 2008). In fact, "bilingual education programs in NT had been effectively stripped back by various phases of government intervention" since 1998 (Wilson, 2014). Later, with only five hours of instruction per day, this may impact the implementation of the language and cultural-based programs (Godinho et al., 2017). In response to that, Spillman (2017) contended that the English-only policy led to the abandonment of support for bilingual literacy agendas that had received a policy authorisation since 1972 .

Therefore, this decision somewhat disregards the International labour convention concerning the integration and protection of Indigenous populations in Australia (Kinslow-Harris, 1968). Accordingly, as a member nation of ILO (International Labour Organisation), the Australian Government should protect the Indigenous and other Tribal populations (Commonwealth, 1973), including the children belonging to the populations. In which they "shall be taught to read and write in their mother tongue or the language commonly used by the group to which they belong". Also, the provision shall be made for a gradual "transition from their first language to the national or official language of the country". Equally important, the appropriate "measures shall be taken to preserve the vernacular language". Thus, it can be contended that the Australian Government has broken the academic promise which they had agreed on in 1973.

Although Henrard (2007) asserted that language rights are just as solid as the government policies, nonetheless, without the unequivocal protection in law, Aboriginal people have no control to protect their children matters over the NT government's policy (Liddicoat, 2008).
From the aforementioned educational perspectives and the rapidly changing system on educational language policy in NT, it can be concluded that shifting bilingual education policy to the privileging English-only instruction show how complicated the NT community languages ecologies are and how the classroom practice put it into a different path. Therefore, the ambivalent attitude of educational policy in NT should trigger researchers, practitioners, and policymakers' efforts and thoughts to conduct an effective way of teaching and learning for Aboriginal students in NT schools, Australia.

\section{Discussion}

In 2008, Malcolm Brough (The Minister of Aboriginal Affairs) had advised NT schools to advocate an English-only approach as language instruction in the first half of school's periods (Devlin et al., 2017). The reason behind this assertion was to "close the gap" and improve Aboriginal students' language proficiency results on National Assessment Program Literacy and Numeracy or NAPLAN (Devlin, 2010). As a consequence, NT Aboriginal community was shocked by the sudden announcement, especially when they are expecting the Government to protect their children's right to learn with and in their first language (Commonwealth, 1972). As a term, English-only approach is where English is the only language instruction used for teaching and learning, even though there is a recognition of the existences of other languages spoken by students or represented in the community (Lesson-Hurley, 2000).

However, as far as the scholars' concern, one of the limitations of the English-only approach in NT school is the existence of 'disparity gap' in sociocultural between teachers and students. According to Crago (1988), cultural disparities between students and teachers in communicative interaction practices have pivotal implications for teaching-learning progress in the classroom.

This contention has been acknowledged by some scholars (e.g. Lessard et al., 2015; Krause \& Prinsloo, 2016), as they believed of how cultural discrepancies influence the incompatible teaching-learning outcome. Similarly, Lowell \& Devlin (1998) argue that the cultural discontinuity between home and school in the Aboriginal environment results in the classroom interlocutor's incommunicative interaction, which means that English-only approach could contribute to the Aboriginal school failure in NT. In addition to that, the evidence from Moses \& Wigglesworth's (2008) discourse analysis research suggests that "Englishonly approach has stimulated specific behaviour patterns" in Aboriginal students, which creates dysfunctional discourse. They believe that this approach hinders active participation of Indigenous students in the classroom interaction. 
Another limitation of the English approach in NT schools is because non-Aboriginal teachers have a tendency to create a monolingual space, yet Aboriginal children convey different linguistic repertoire to the classroom (Angelo \& Carter, 2015). However, this mismatch exchanges cannot be judged as solely a teacher's fault, but rather to perceive it as an educational challenge in the school policy (Angelo, 2013). One way to eclipse this limitation is by providing more Aboriginal teaching assistants in NT school system (Lowell \& Devlin, 1998). Because with the presence of a teaching assistant, "the use of pragmatic code-switching" in the classroom can be reduced (Lowell \& Devlin, 1998). In fact, the distribution of fully-qualified teachers compare to the population of the Indigenous student population is on the disproportion rate (Van Gelderen, 2017). According to Cummins (2000), language's instruction at school is far more cognitively demanding than every day's style in the casual conversation. Thus, Aboriginal students cannot interpret language instruction (English) and show no indication that they will understand the instruction given and whatsoever.

A clear example was found in Moses and Wigglesworth's (2008) study when non-Aboriginal teachers were using English in interrogative forms; the students were giving uncooperative responses. It shows how important the role of the first language is; thus, non- Aboriginal educators must have sensible states of mind towards the language codes the children convey to the class and should regard and use their 'home' language as a medium of instruction (Malcolm, 2003). I contend that the English-only approach in the NT classroom impedes the first language of Indigenous students as well as delayed the learning of English (L2) itself, thereby hinders its educational effectiveness.

\subsection{The Significance of Mother Tongue}

The successful bilingual education is underlying in the fundamental principle of literacy development and first language acquisition. Krashen (1996) asserted that giving children quality education in their primary language will provide them with the knowledge to comprehend, and the literacy to transfer across languages. This suggests that a proper bilingual program will give the children a comprehensible input and prior knowledge of the first and second language, also will stimulate their literacy development simultaneously. He illustrated this philosophy by presenting the analogy sample of "The Paris Argument", in which how an individual could transmit the specific information faster and more comprehensive from first language (English) to the second language (French), rather than by understanding it directly as one acquires French. This analogy confirms that the background of knowledge and subject matter of the individual's first language significantly related to the provision of one' second language literacy independently. There are considerable empirical shreds of evidence consistently support the significant benefits of the first language in bilingual education (see Baker, 2000; Cummins, 2000; Ganal, 2014; Silburn et al., 2011; SkutnabbKangas, 2000). In Silburn's et al. (2011) work, for example, they contend that the development of first language literacy on Aboriginal children affects the second/additional literacy in another language, in this context, English. In a similar vein, Ganal (2014) approved that bilingualism has a positive impact on children's linguistic and educational progress as they gain a deeper understanding on how language system is worked and then how to use it effectively. Further, in her research, Ganal found that when children develop and practice their literacy in both languages, they can process the languages system by comparing and contrasting both languages simultaneously.

Moreover, this claim is supported by the works of Cummin's (2000) and Skutnabb-Kangas's (2000), in which they asserted that bilingual education might also develop the flexibility of children's thinking as a result of processing information in two different languages. As a result, bilingual children perform better in their personal, educational development when teachers effectively teach them the first language and help them develop literacy in that language. In contrast, when children are forced to disregard their mother tongue, their conceptual base for learning is weakened; thus, halt the development of their second language (Baker, 2000). Therefore, mother tongue promotion at school will assist both short and long-term literacy development of Aboriginal students' second/additional language (English).

Building on empirical pieces of evidence above, it is hoped that in the future, the English language will be integrated and taught in the ongoing first language (Aboriginal) teaching, rather than in a monolingual (English) learning space. As supported by Cummins (2000), the opportunity given to minority languages (Aboriginal languages) as a language instruction will not hurt children academic performance, but instead provide them with a vehicle for self- determination to incorporate their primary language and culture into the school system, regarding making the school as an instrument of culture and language preservation rather than destruction. In line with Cummins' claim, Devlin (2009) endorsed this program significantly as she found a positive outcome of the bilingual education program in her research. The outcome from her study shows that bilingual program students perform as good as monolingual program students in English Academic skills, although they are being given considerably less English instruction. 
Moreover, in another multilingual community like in the United States, August \& Shanahan (2006) founded that bilingual instruction employs a restrained but substantial positive impact on minority students' English academic attainment. In short, based on some major research concerning minority children and bilingual program in relation to English literacy, it is found that there is no indication that bilingual instruction hinders students from Academic achievement either in their first language or English.

A bilingual program was initially created to contribute to the vitality of Aboriginal languages. As written in UN Declaration on The Right of Indigenous Peoples (2010), "Indigenous peoples have the right to establish and control their educational system and institutions providing education in their own languages, in a manner appropriate to their cultural methods of teaching and learning". Although this statement was belated, formally supported by the Federal Government of Australia, the bilingual programs are somehow being overlooked by The NT authorities. This decision has been highly criticised by most scholars (Wilkins, 2008; Devlin, 2009; Waller, 2011). As a result, in 2012, Scrymgour (a former member of Northern Territory legislative assembly) softened her position and re-construct the NT educational policy and reboot classroom's language instruction. In this way, the bilingual program is not only elevated the status of Aboriginal languages as the legitimate vehicle for cultural and intellectual exchange at school but also provide a solid foundation for students' literacy development in both 'home' and 'school' language. These results thus confirmed the significance of solid connections between languages in community and schools as an essential step to improve English literacy in remote, multilingual school's context (Wilson et al., 2017).

\subsection{Transitional Bilingual Programs}

Principally, the goal of transitional programs is to enhance students' proficiency in English as a second or additional language. In such programs, home language is used for the instructional assistance until learners have given an adequate level of English language skills and proficiency. The expectation is that students will be ready to move out to the Englishonly classroom after three years. However, this contention is criticised by Lessow-Harley (2000), she viewed this program as an unrealistic agenda because it seems impossible to expect children to master their L2 in a three-year period. However, a country like China has taken major steps to implement this transitional bilingual program (Wang, 1986). The results from Wang's research suggested that these transitional bilingual programs have increased academic achievement as well as improve children's' participation and attendance. Canada also illustrates an obvious example, with notable success and progress of its "Dual (French- English) immersion programs" for English speakers (Lessow-Hurley, 2000). In fact, the transitional language programs have been established to support Indigenous and immigrant minorities, some with "the goal of transitioning" younger students from their primary languages to French, while others with "the purpose of preserving" their heritage language (Cummins, 1984). In a similar vein, Sweden provided transitional bilingual programs for its immigrant children, with the goal of enabling them to function fully both in Swedish and their 'home' language, where Swedish is taught initially as a second language by the fifth or sixth grade (Lesson-Hurley, 2000).

Another successful attempt of transitional bilingual programs was adopted by The Philippines Government, in which they formulate an effective way of teaching L1 literacy and dominant language in minority ethnic schools (Martin, 2018). Further, the transitional bilingual program has been contended and promoted as a more suitable approach for young learners rather than English-only programs (Cummins, 2000). This approach may enhance learning in all curricular focuses (Devlin et al., 2017), since this approach enables young students to carry out a powerful, affirming function of both languages. Hence, from the empirical confirmations and practical implementations, it is clear that transitional bilingual programs have produced generally positive results in a broader multilingual context.

\subsection{Translanguaging: Alternative Approach}

Although NT school has succeeded in maintaining its stable bilingual education for such a long-time, there has been a great pressure from many factions to halt this program and move to a typical English-only standard classroom (Simpson et al., 2009). Thus, another approach is required to tackle this issue, namely, "translanguaging". According to Baker (2011), translanguaging is "the process of making meaning shaping experiences, gaining understanding and knowledge through the use of two languages". This approach, therefore, extends the concept of 'languaging' by providing a lens for assessing the correlation between one's language practices and multilingual or multidirectional language learning (Wei, 2011). Further, translanguaging conveys a multilingual awareness, which is defined as a language awareness that develops and enhance learners' consciousness and sensitivity to the forms of functional languages (Carter, 2003). Furthermore, this approach can be instigated in the teaching-learning process since its function is to differentiate the discourse between interlocutors and increase students' participation in the classroom (Martin-Beltrán et al., 2017). This intermediation aids Aboriginal children to find a more appropriate mother-tongue version of their English phrases. 
Since multilingual learners (Aboriginal) are essential to this study, therefore a translanguaging approach can be seen as a fluid practicality approach that goes beyond a socially constructed language and an educational system to engage diverse students in "multiple meaning-making schemes" and prejudices (Garcia \& Wei, 2014). Even though code-switching has a long tradition in educational research, translanguaging offers the fluidity of multilingual practices as an asset in making sense of the context in which teachers and students are immersed (Creese \& Blackledge, 2010). A researcher like Canagarajah (2006) have studied the multilingual and multimodal characteristics of translanguaging in a diverse community. He asserted that the use of technology allows the blending of semiotic elements (text, drawing, pictures) and the multimodal final product (Power-Point presentation). This constituting process, therefore, creates particular attention for both teacher and student as a discourse function. Therefore, the concept of translanguaging is used in the classroom as an effort to understand how teachers and students express their thoughts through more than one language interchangeably. Also, to mediate and combine intellectual endeavour with an array of one's language background and knowledge (Martin-Beltran et al., 2017).

\section{Conclusion}

In conclusion, this paper has attempted to explore significant issues that cause ineffective English-only program at NT schools in Australia. Drawing predominantly from 47 empirical studies, the writer affirmed that the English-only approach is not proper for young Aboriginal learners, because the English language was scarcely exposed in multilingual societies like the Northern Territory. Factors like 'socio-cultural gap' were found to be influencing the ineffective English-only classroom in the NT. Besides, there have been a number of studies also mentioning how monolingual (English-only) space created by non-Aboriginal teachers deter Indigenous students' responses in the classroom setting. Interestingly, some alternative approaches have been employed in some countries. The 'transitional bilingual programs' and 'translanguaging approach' are seen clinically relevant to the needs of Aboriginal schools in NT since it gives Aboriginal students self-determination to incorporate their home language and culture into a school system. Also, the first language of Aboriginal students plays a key role in the outcome of students' English literacy.

The shreds of evidence from this study suggest that it is fundamental to provide sustainable transitional-bilingual programs for Indigenous inhabitants of Northern Territory (NT). One of which is by providing a teacher training-based centre for both Aboriginal teachers/teaching assistant and nonAboriginal teachers in NT schools. Specifically, by understanding Aboriginal learning features and communications relevant to the specific region in which they are working. In addition, the primary focus for the authority in NT is to foster a collaborative approach between non-Indigenous and Indigenous teachers. In regard to creating an effective classroom instruction, notably in concentrating on what was currently being done in the early school programs to a possible experimental setup program in the future.

\section{Acknowledgement}

This library research was conducted during the writer's master program at Monash University, Australia. The advice given by Dr. Louisa Willoughby from applied linguistics department has been a great help in finishing this paper. I hope this paper will provide insight into an earlier researcher who interested in language and multilingual studies.

\section{References}

Anderson, G., \& Harrison, K. (2007). Global language hotspots. Retrieved June 2, 2018 from http://www.swarthmore.edu/SocSci/langhotspot s/index.html.

Angelo, D. (2013). Identification and assessment contexts of Aboriginal and Torres Strait Islander learners of Standard Australian English: Challenges for the language testing community. Papers in Language Testing and Assessment, 2(2), 67-102.

Angelo, D., \& Carter, N. (2015). Schooling within shifting landscapes: Educational responses in complex Indigenous language contact ecologies. Multilingualism and Language in Education: Current Sociolinguistic and Pedagogical Perspectives from Commonwealth Countries. Cambridge: CUP.

August, D. E., \& Shanahan, T. E. (2006). Developing literacy in second-language learners: Report of the National Literacy Panel on LanguageMinority Children and Youth. Lawrence Erlbaum Associates Publishers.

Australian Human Rights Commission. (2010). The Community Guide to the UN Declaration on the Rights of Indigenous People. Retrieved from https://declaration.humanrights.gov.au/sites/defa ult/files/document/publication/decl aration_com munity_guide.pdf

Baker, C. (2000). A parents' teachers' guide to bilingualism (Second Edition). Clevendon, England: Multilingual Matters.

Baker, C. (2011). Foundations of bilingual education and bilingualism (Vol.79). Clevedon: Multilingual Matters. 
Biddle, N. (2014). Spreadsheet: Number of Indigenous language speakers, 2006-2011. Retrieved May 30, 2018, from http://caepr.anu.edu.au/Indigenous-languageusage.php.

Canagarajah, A.S. (2006). The place of World Englishes in composition: Pluralisation continued. College Composition and Communication, 57, 586-619.

Carter, R. (2003). Language awareness. ELT Journal, 57(1), 64-65.

Chavez, L. \& Amselle, J. (1997). Billingual Education Theory and Practice: Its Effectiveness and Parental Opinions. NASSP Bulletin, 81(586), pp.101-106. Commonwealth of Australia. (1973). Parliamentary debates. Retrieved June 1, 2018 from http://goo.gl/9aCMdd.

Crago, M. (1988). Cultural context in communicative interaction of Inuit children. PhD dissertation, McGill University.

Creese, A., \& Blackledge, A. (2010). Translanguaging in the bilingual classroom: Pedagogy for learning and teaching? Modern Language Journal, 94(1), 103-115.

Cummins, J. (1984). Billigualism and Special Education: Issues in assessment and pedagogy. San Diego, CA: College-Hill Press.

Cummins, J. (2000). Language, power and pedagogy. Bilingual children in the crossfire. Clevedon, England: Multilingual Matters.

Devlin, B. (2009). Bilingual education in the Northern Territory and the continuing debate over its effectiveness and value. Paper presented at the AIATSIS Research Symposium, Bilingual Education in the Northern Territory: Principles, policy and practice, Canberra, June 26.

Devlin, B. (2010). Evidence, policy and the 'Step' model of bilingual education in the NT: A brief outline. Paper based on a presentation given at a Public Forum in Darwin on September 9, 2010. Retrieved from http:// www.ns.uca.org.au/wpcontent/uploads/2010/09/Evidence-inBilingual-Education.pdf

Devlin, B., Disbray, S. and Friedman Devlin, N. (2017). History of bilingual education in the Northern Territory. Singapore: Springer.

Ganal, N. (2014). Demographic Profile and Perception of Teachers and School Heads on Mother Tongue as Language of Instruction. Indian Journal of Management Science, 4(3), 44.

Garcia, O., \& Wei, L. (2014). Translanguaging: Language, bilingualism and education. New
York, NY: Palgrave Macmillan.

Godinho, S., Woolley, M., Scholes, M., \& Sutton, G. (2017). Literacies for remote schools: Looking beyond a one size fits all approach. Literacy Learning: The Middle Years, 25(1), 28.

Henrard, K. (2007). Language Rights in South Africa: An adequate level of minority protection?' In Matthias Koenig and Paul de Guchteneire (eds). Democracy and human rights in multicultural societies. Aldershot: UNESCO/Ashgate. pp.185-216.

Kinslow-Harris, J. (1968). Linguistics and Aboriginal education: A practical use of linguistic research in Aboriginal education in the Northern Territory. Australian Territories, 8(1), 24-34. http://www.als.asn.au/proceedings/als2007/liddi coat.pdf

Krashen, S., D. (1996). Under attack: the case against bilingual education. Culver City, Calif: Language Education Associates.

Krause, L.S \& Prinsloo, M. (2016) Translanguaging in a township primary school: Policy and Practice. Southern African Linguistics and Applied Language Studies, 34:4, 347- 357, DOI: 10.2989/16073614.2016.1261039

Lessard, S., Caine, V., \& Clandinin, D.J. (2015). A narrative inquiry into familial and school curriculum making: attending to multiple worlds of Aboriginal youth and families, Journal of Youth Studies, 18(2), 197-214, DOI: 10.1080/13676261.2014.944121

Lessow-Hurley, J. (2000). The Foundations of Dual Language Instruction. Addison Wesley Longman, Inc.

Liddicoat, A., J. (2008). Models of national government language-in-education policy for indigenous minority language groups'. In Timothy J. Curnow (ed.) Selected papers from the 2007 Conference of the Australian Linguistic Society. Adelaide.

Lowell, A. \& Devlin, B. (1998). Miscommunication between Aboriginal Students and their NonAboriginal Teachers in a Bilingual School. Language, Culture and Curriculum, 11(3), $367-$ 389, DOI: 10.1080/07908319808666563

Manning, M, L. \& Baruth, L, G. (2004). Multicultural education of children and adolescents. Pearson Education, Inc.

Marmion, D., Obata, K., \& Troy, J. (2014). Community, identity, wellbeing: The report of the Second National Indigenous Languages Survey. Canberra: Australian Institute of Aboriginal and Torres Strait Islander Studies. 
Martin, I. (2018). Reconceptualising English education in a multilingual society: English in the Philippines. Singapore: Springer.

Martin-Beltrán, M., Guzman, N., \& Chen, P. (2017). 'Let's think about it together:' how teachers differentiate discourse to mediate collaboration among linguistically diverse students. Language Awareness, 26(1), 41-58. DOI: $10.1080 / 09658416.2016 .1278221$

Meakins, F. (2014). Language contact varieties. In H. Koch \& R. Nordlinger (Eds.), e languages and linguistics of Australia: A comprehensive guide, 365-416. Boston: De Gruyter Mouton.

Moses, K. R., \& Wigglesworth, G. (2008). The silence of the frogs: Dysfunctional discourse in the 'English-only' Aboriginal classroom. In J. Simpson \& G. Wigglesworth (Eds.), Children's language and multilingualism. London: Continuum.

Mufwene, S. S., \& Vigouroux, C. B. (2012). Individuals, populations, and timespace: Perspectives on the ecology of language. Cahiers de Linguistique, 38(2), 111-138. Special issue, Sociolinguistique comme construction, Françoise Gadet (Ed.).

NILS. (2005). National Indigenous Languages Survey Report 2005. Canberra.

Silburn, S. R., Nutton, G., McKenzie, J. W., \& Landrigan, M. (2011). Early years English language acquisition and instructional approaches for Aboriginal students with home languages other than English: A systematic review of the Australian and international literature. Darwin: Menzies School of Health Research.

Simpson, J., Caffery, J., \& McConvell, P. (2009). Gaps in Australia's Indigenous language policy: Dismantling bilingual education in the Northern Territory. AIATSIS Discussion Paper, 24.

Skutnabb- Kangas, T. (2000). Language, power, and pedagogy: Bilingual children in the crossfire. Clevedon, England: Multilingual Matters

Spillman, D. (2017). A Share in the Future . . Only for Those Who Become Like 'Us': Challenging the 'Standardisation' Reform Approach to Indigenous Education in the Northern Territory. Australian Journal of Indigenous Education, 46(2), 137- 147. DOI:10.1017/jie.2017.3

Van Gelderen, B (2017). Growing Our Own: A 'two way' place based approach to Indigenous initial teacher education in remote Northern Territory. Australian and International Journal of Rural
Education, 27(1), pp. 14-28.

Waller, L. (2011). Learning in both worlds. Inside Story: Current affairs and culture from Australia and beyond. (Essays and reportage). Retrieved from http://insidestory.org.au/learning-in-bothworlds

Wang, P., C. (1986). A bilingual education lesson from China. Thrust, 16(1), 38-39.

Wei, L. (2011). Moment analysis and translanguaging space: Discursive construction of identities by multilingual Chinese youth in Britain. Journal of Pragmatics, 43, 1222-1235. DOI: $10.1016 /$ j.pragma.2010.07.035

Wigglesworth, G., Simpson, J., \& Vaughan, J. (2018). Language practices of Indigenous children and youth. London: Palgrave Macmillan UK

Wilson, B. (2014). A share in the future: Review of Indigenous education in the Northern Territory. Darwin: NT Department of Education.

Wilson, B., Quinn, S., Abbott, T., \& Cairney, S. (2017). The role of Aboriginal literacy in improving English literacy in remote Aboriginal communities: an empirical systems analysis with the Interplay Wellbeing Framework. Educational Research for Policy and Practice, 17(1), 1-13. DOI: 10.1007/s10671-017-9217-z 